\title{
Activating PIK3CB Gene Mutation
}

National Cancer Institute

\section{Source}

National Cancer Institute. Activating PIK3CB Gene Mutation. NCI Thesaurus. Code C153395.

A change in the nucleotide sequence of the PIK3CB gene that results in constitutive activation of phosphatidylinositol 4,5-bisphosphate 3-kinase catalytic subunit beta isoform and its downstream signaling pathways. 